\title{
Two tests of a fear-motivated theory of exploration'
}

DAVID LESTER

WELLESLEY COLLEGE

It was predicted from a fear-motivated theory of exploration that defecating rats should show extremes of activity in an open-field test. This prediction was supported. An explanation of a reported sex difference in exploratory behavior that was based on this fear-motivated theory of exploration was not supported.

Lester (1967) proposed a theory of exploration in which mild increases in the fear level of an organism increases the exploratory tendencies of that organism. As the fear level of the organism rises still further the exploratory tendencies of the organism begin to decrease until, at very high fear levels, avoidance behavior is shown. If defecation is an index of fear level and if defecation occurs at both intermediate and high fear levels, then defecating rats will show either maximum exploratory behavior (at intermediate fear levels) or minimal exploratory behavior (at very high fear levels). Nondefecating rats will show an intermediate level of activity.

Lester also reported the existence of a sex difference in the exploratory behavior of rats. For male rats food deprivation increased exploratory behavior whereas for female rats deprivation decreased exploratory behavior. Lester advanced an explanation of this phenomenon that was predicated upon male rats having a lower basal fear level than female rats. Increasing deprivation was assumed to increase the fear level of the animals (Mowrer, 1960), and this has different effects on male and female rats since their basal fear levels differ. A crucial test of this explanation would be to investigate the fear levels of satiated male and female rats.

The present experiment was designed (a) to see whether a U-shaped function obtains between exploratory activity and defecation, and (b) to see whether satiated female rats defecate more than satiated male rats, in an open-field test of exploration.

\section{Method}

The Ss were 30 male and 30 female rats from the Charles River Breeding Laboratories, strain CD. They arrived in the laboratory aged 60 days. They were housed singly with ad lib food and water.

The open field was a table $46-1 / 4$ in. long $\times 20$ in. wide. It was elevated 30 in. and was enclosed by walls on three of the sides (one long side and both short sides). The field was divided into ten
$10 \times 9$ in. squares. A different cardboard floor was placed on the field for male and female rats.

On Days 1 and 2 animals were allowed to rest. On each of Days 3,4, and 5, 10 female and 10 male rats were tested. Each animal was placed on one square of the field and allowed to explore for $5 \mathrm{~min}$. The number of squares entered during each minute of the test period was noted. (An entry was defined as made into a square when all four paws of the rat had entered the square.) The number of fecal boli defecated was also noted for each rat. After each rat was tested the floor of the field was brushed clean. The floor cover was changed only when rats of a different sex were tested.

\section{Results}

Four of the 30 females and 18 of the 30 males defecated in the field. This difference is significant on a chi-square test with Yates' correction (Siegel, 1956; $\chi^{2}=12.13$, df $=1, \mathrm{p}<0.001$ ).

For the activity scores (the number of squares entered), there were no significant differences between male and female rats. Seventeen female and 13 male rats were above the median activity score $\left(x^{2}=0.8, \mathrm{df}=1, \mathrm{~ns}\right)$. The median activity scores were 27-1/2 squares for female rats and 21 squares for male rats. Male and female rats did not differ in the number of rats freezing for at least $1 \mathrm{~min}$ of the 5 min test period. Fourteen of the males and 13 of the females did.

To investigate the relationship between defecation and activity, the 60 rats were divided into quartiles (insofar as was possible) on the basis of their activity scores and the rats in each quartile classified as defecators or nondefecators (see Table 1). A chi-square test was carried out comparing the two extreme quartiles with the two middle quartiles. The difference was significant $\left(X^{2}=9.9\right.$, df $=1, p<$ $0.01)$. This means that, in general, those rats that defecated tended to have extreme activity scores,

Table 1. Activity Scores of Rats Defecating and Not Defecating in the Open-field. The number of rats defecating and not defecating in each activity quartile is shown.

\begin{tabular}{cccc}
$\begin{array}{c}\text { First } \\
\text { quartile } \\
\text { (least } \\
\text { active) }\end{array}$ & $\begin{array}{l}\text { Second } \\
\text { quartile }\end{array}$ & $\begin{array}{c}\text { Third } \\
\text { quartile }\end{array}$ & $\begin{array}{c}\text { Fourth } \\
\text { quartile } \\
\text { (most } \\
\text { active) }\end{array}$ \\
\hline
\end{tabular}

\begin{tabular}{lrrrr}
\hline Defecators & 11 & 1 & 4 & 6 \\
Non-defecators & 4 & 14 & 12 & 8 \\
\hline
\end{tabular}


either very low or very high, whereas nondefecators tended to have intermediate activity scores.

Rats in the second quartile differed significantly $(p<0.05)$ from rats in the first and fourth quartiles in their defecation behavior. Rats in the third quartile differed significantly in defecation behavior from rats in the first quartile.

\section{Discussion}

This experiment indicates that rats who defecate do tend significantly to have extreme activity scores, and this phenomenon is in accord with the fearmotivated theory of exploration proposed by Lester (1967). This result may account for the inconsistent correlations reported by other workers between activity and defecation. A simple linear correlation would not detect the U-shaped function that obtains between the variables. ${ }^{2}$

This experiment clearly refutes the idea that satiated female rats have a higher fear level than satiated male rats, if defecation is considered to be a valid measure of fear levels in rats. In this experiment, male rats defecated more than female rats. Results from other experiments are reasonably consistent with this result, even though these studies used rats of different strains than that used in this experiment. For example, Candland et al (1967) using rats of the strain Carnsworth CFE found no sex differences in defecation behavior, but female rats had a higher heart rate than did male rats. Snowden et al (1964), using Wistar rats, found that the females had a higher heart rate than the males. Furthermore, Snowden et al reported that the heart rate measure was negatively correlated to the defecation measure, and so it appears that a high heart rate is indicative of low emotionality. Thus, the studies indicate that female rats are less emotional (that is, have a higher heart rate) than male rats.

It may be concluded that the basic fear-motivated theory of exploration proposed by Lester (1967) may have some validity. However, the specific explanation of the sex difference in exploration based on this theory was not supported. An explanation of this sex difference in exploration must be sought elsewhere.

\section{References}

CANDLAND, D. K., PACK, K. D., \& MATTHEWS, T. J. Heart rate and defecation frequency as measures of rodent emotionality. $J$. comp. physiol. Psychol., 1967, 64, 146-150.

LESTER, D. Sex differences in exploration: toward a theory of exploration. Psychol. Rec., 1967, 17, 55-62.

MOWRER, O. H. Learning theory and behavior. New York: Wiley, 1960. SIEGEL, S. Nonparametric statistics for the behavioral sciences. New York: McGraw-Hill, 1956.

SNOWDEN, C. T., BELL, D. D., \& HENDERSON, N. D. Relationship between heart rate and open-field behavior. J. comp. physiol. Psychol., $1964,58,423-426$.

Notes

1. This research was supported by Research Grant MH 14404-0l from the National Institute of Mental Health.

2. The fact that the defecating rats consisted mainly of males does not detract from the supporting nature of the results. It would, however, be of interest to see whether the relation would obtain in each sex. In the present experiment, the male rats did show the relationship significantly. There were not enough females defecating in order to examine the relationship for them. 